\title{
Studi Komunikasi Antarpribadi Anak Dengan Orang Tua Tiri
}

\author{
Chaterine Setiawan dan Suzy Azeharie \\ Fakultas Ilmu Komunikasi Universitas Tarumanagara \\ suzya@fikom.untar.ac.id
}

\begin{abstract}
This study discusses the communication between the child and the stepparent and use the theory that consists of communication theory, communication function, the purpose of communication, interpersonal communication, effective interpersonal communication, interpersonal communication role and function of interpersonal communication. This study used a qualitative method with descriptive qualitative approach. The data used in this study consisted of primary data and secondary data. The primary data of the interviews with sources consisting of four children and one stepparent. While the secondary data obtained from other sources such as books and online data searches. The technique of collecting data using interviews, observation, literature review and data searches online. From this research it is known that children who learn about and understand the prospective stepparent before she married biological parents do relatively better than those who do not recognize his step prospective parents before marriage. It is also known that the interpersonal communication of children with stepparents dependent based on the character of the child and the stepparent respectively.
\end{abstract}

Keywords: interpersonal communication, general quality of interpersonal communication, family, step parent

\begin{abstract}
Abstrak
Penelitian ini membahas tentang komunikasi antara anak dengan orang tua tiri dan menggunakan teori yang terdiri dari teori komunikasi, fungsi komunikasi, tujuan komunikasi, komunikasi antarpribadi, komunikasi antarpribadi yang efektif, peranan komunikasi antarpribadi dan fungsi komunikasi antarpribadi. Penelitian ini menggunakan metode kualitatif dengan pendekatan deskriptif kualitatif. Data yang digunakan dalam penelitian ini terdiri dari data primer dan data sekunder. Data primer berupa hasil wawancara dengan narasumber yang terdiri dari empat orang anak dan satu orang tua tiri. Sedangkan data sekunder berupa data yang diperoleh dari buku dan sumber lain seperti penelusuran data online. Teknik pengumpulan data dengan menggunakan wawancara, observasi, kajian pustaka dan penelusuran data online. Dari penelitian ini diketahui bahwa anak yang mengetahui dan mengenal calon orang tua tiri sebelum menikah dengan orang tua kandungnya hubungannya relatif lebih baik dibandingkan anak yang tidak mengenal calon orang tua tirinya sebelum menikah. Selain itu juga diketahui bahwa komunikasi antarpribadi anak dengan orang tua tiri tergantung berdasarkan karakter dari anak dan orang tua tiri masing-masing.
\end{abstract}

Kata Kunci: komunikasi antar pribadi, kualitas umum komunikasi antarpribadi, keluarga, orang tua tiri, 


\section{Pendahuluan}

Sebagai mahluk sosial manusia selalu melakukan proses komunikasi satu dengan yang lain secara sengaja ataupun tidak disengaja yang bertujuan untuk memenuhi kebutuhan fisik ataupun jasmani. Komunikasi juga terjadi dalam keluarga karena keluarga adalah tempat pertama bagi seseorang untuk berkomunikasi dalam kehidupan sehari- hari.

Umumnya bentuk keluarga inti yang dikenal terdiri dari ayah, ibu dan anak hasil dari pernikahan. Akan tetapi fenomena anak yang diasuh oleh orang tua tiri tidak dapat dihindarkan di masyarakat. Sebab tidak menutup kemungkinan dalam sebuah keluarga terjadi kejadian yang tidak terduga terjadi seperti kehilangan salah satu orang tua baik ayah atau ibu dan kemudian digantikan oleh orang tua tiri. Padahal persepsi orang tua tiri pada masyarakat identik dengan memiliki sifat kejam dan tidak adil.

Stigma orang tua tiri yang terbentuk pada masyarakat cukup buruk. Hal itu terjadi disebabkan oleh pemberian label oleh utamanya media massa pada orang tua tiri khususnya pada ibu tiri. Seperti pada tahun 1973 film Ratapan anak Tiri karya sutradara Sandy Suwardy Hassan (Film Indonesia, n.d.). Judul lagu yang sama dalam film tersebut ciptaan Mashabi dan dinyanyikan oleh penyanyi Indonesia yaitu Iis Dahlia dirilis dengan lirik yang menyentuh sehingga membuat persepsi masyarakat bahwa orang tua tiri memiliki sikap kejam dan tidak adil (HP Records, 2015). Tidak lupa sejak kecil dongeng rakyat berjudul Bawang Putih dan Bawang Merah juga membuat persepsi buruk perilaku orang tua tiri terutama pada ibu tiri (Pramesty, 2012).

Belum banyak diketahui komunikasi antara anak dengan orang tua tiri dalam kegiatan sehari-hari di suatu keluarga. Ketidaktahuan tersebut menimbulkan rasa ingin tahu guna mengerti pola komunikasi antarpribadi yang terjadi antara anak dengan orang tua tiri.

Pada kenyataannya komunikasi antarpribadi dalam keluarga tidak bergantung pada status kandung ataupun tiri melainkan ditentukan oleh usaha untuk membangun komunikasi antarpribadi dan karakter masing-masing. Karena menurut Robertus Belarminus yang mengutip Reza Indragiri Amriel hubungan orang tua tiri dan anak tidak selalu tidak harmonis. Kasus ibu tiri yang agresif dan melakukan tindakan kekerasan pada anak terjadi karena tidak ada proses membangun komunikasi yang baik sebelum pernikahan dilangsungkan seperti pembicaraan mengenai fungsi atau peran masing masing pihak sebelum berumahtangga yang merupakan salah satu sumber penyebab masalah (Belarminus, 2015).

Berdasarkan uraian dan fakta di atas penulis tertarik untuk melakukan penelitian mengenai komunikasi antarpribadi yang terjalin antara anak dengan orang tua tiri yang bertujuan untuk mengetahui bagaimanakah komunikasi anak dengan orang tua tiri di dalam keluarga. 


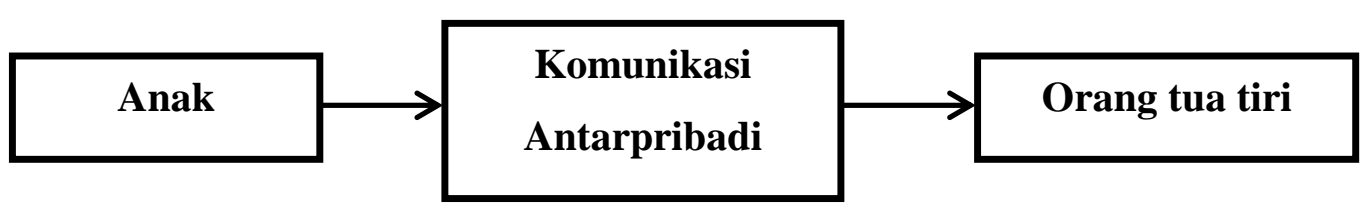

Gambar 1: Kerangka Pemikiran (Sumber: Penulis)

Pada gambar 1 merupakan kerangka pemikiran yang penulis gunakan dalam penelitian ini yaitu bagaimana komunikasi antarpribadi yang terjalin antara anak dengan orang tua tiri dalam keluarga.

\section{Ruang Lingkup}

Dalam penelitian ini penulis membatasi ruang lingkup penelitian dilakukan pada empat orang anak yang memiliki orang tua tiri. Dengan topic penelitian Studi Komunikasi Antarpribadi Anak dengan Orang Tua Tiri, maka yang menjadi obyek penelitian ini adalah empat orang anak yang memiliki orang tua tiri dan subyek penelitian adalah komunikasi antarpribadi yang dilakukan oleh anak dengan orang tua tiri.

\section{Tujuan Penelitian}

Berdasarkan latar belakang penelitian di atas maka tujuan penelitian ini adalah untuk mengetahui bagaimana komunikasi anak dengan orang tua tiri di dalam keluarga.

\section{Manfaat Penelitian}

1. Hasil penelitian ini diharapkan dapat menambah wawasan peneliti lain yang menjadikan hasil penelitian ini sebagai bahan perbandingan maupun referensi dengan obyek penelitian yang sama guna mengembangkan ilmu komunikasi.

2. Dapat memberikan kontribusi pada dunia ilmu komunikasi mengenai komunikasi antarpribadi anak dengan orang tua tiri.

\section{Metode Penelitian}

Dalam penelitian ini penulis melakukan penelitian kualitatif dengan model deduksi. Teori dijadikan alat penelitian utama sejak memilih dan menmukan masalah, membangun hipotesis hingga proses pengujian data atau analisa data. Untuk memperkuat data penelitian maka digunakan metode pengumpulan data dengan melakukan wawancara dan observasi dan studi kepustakaan serta penelusuran data online dalam penelitian ini. Keempat narasumber penelitian ini adalah sebagai berikut:

1. Narasumber pertama adalah Albert Triyono (22 tahun) yang sedang menjalani pendidikan S1 di Universitas Pamulang Tangerang, Banten jurusan Satra Inggris angkatan 2012. Albert merupakan anak terakhir dari tiga bersaudara. Albert Triyono beragama Katolik dan memiliki ayah tiri bernama Darwin Marudin (72 tahun). Ayah tirinya berasal dari Padang 
dan beragama Islam dengan pendidikan terakhir lulusan D3 Pembangunan Sipil. Darwin Marudin merupakan seorang wirausaha yang membuka usaha pencucian mobil.

2. Yang kedua adalah Maria Novalia Manik (22 tahun) yang sedang menjalani pendidikan S1 di Universitas Sultan Ageng Tirtayasa Serang, Banten jurusan Hukum Perdata angkatan 2012. Ibu tiri Maria bernama Clara Sidabutar (38 tahun) seorang ibu rumah tangga, beragama Katolik dan berasal dari Batak. Pendidikan terakhir Clara Sidabutar adalah lulusan Sekolah Menengah Atas.

3. Sedangkan narasumber yang ketiga dan keempat merupakan sepasang anak kembar bernama Hannas Natanael dan Hanniel Natanael. Mereka berumur 20 tahun yang saat ini Hannas sedang menjalani pendidikan S1 di Universitas Pelita Harapan Tangerang, Banten jurusan Teknik Elektro angkatan 2013. Hannas merupakan anak ketiga dari empat bersaudara. Sedangkan Haniel Natanael sedang menjalani pendidikan S1 di Universitas Pelita Harapan Tangerang, Banten jurusan Teknologi Pangan angkatan 2013. Haniel merupakan anak terakhir dari empat bersaudara.

Selain itu teknik analisis data dalam metode penelitian penulis ini adalah deskriptif kualitatif dan juga menggunakan model deduksi. Penulis menjadikan teori sebagai alat penelitian utama sejak memilih dan menemukan masalah, mebangun hipotesis hingga pada proses pengujian data atau analisis data dan hal ini sesuai dengan premis yang dikemukakan oleh Burhan Bungin (Bungin, 2010: 264).

\section{Hasil Penemuan dan Diskusi}

Berdasarkan wawancara dengan keempat narasumber dan satu orang tua tiri, narasumber pertama yaitu Albert Triyono mengatakan bahwa komunikasi yang ia lakukan dengan ayah tirinya terjadi dalam kehidupan sehari-hari dari waktu ke waktu. Ia memulai berkomunikasi dengan Darwin Marudin (calon ayah tirinya) sejak sebelum ibu kandungnya menikah lagi sampai mereka menikah dan kini tinggal satu atap bertiga di daerah Pamulang. Ibu Albert, Sriyati yang sebelumnya beragama Katolik ketika menikah dengan Darwin Marudin berpindah agama menjadi muslim sementara Albert tetap beragama Katolik.

Saat awal keduanya menikah hingga saat ini Albert merasakan komunikasi antarpribadi dengan ayah tirinya itu berjalan cukup lancar. Bahkan ia mengakui bahwa kualitas hubungannya dengan Darwin Marudin semakin hari semakin baik. Albert mengungkapkan bahwa seringnya ia berkomunikasi dengan ayah tirinya disebabkan ayah tiri Albert tersebut pada masa awal pernikahan bekerja pada sebuah proyek pembangunan selesai maka bila proyek itu selesai dikerjakan Darwin Marudin akan tinggal di rumah sampai ia mendapatkan proyek baru.

Untuk keperluan kuliah, Albert meminta bantuan keuangan kepada ayah tirinya. Dan ayah tiri Albert memberikan respon positif dengan membantu Albert sebagai bagian dari bentuk tanggung jawab seorang ayah. Ia membayarkan uang kuliah Albert dari uang tabungan hasil perkerjaannya di proyek. Sejak itulah, 
menurut Albert, hubungan komunikasinya dengan ayah tiri yang awalnya terasa canggung dan kaku berangsur membaik. Saat ini Darwin Marudin sudah memiliki pekerjaan tetap yaitu mengelola sebuah tempat usaha pencucian mobil. Meskipun begitu Albert tetap berkomunikasi melalui telepon dengan ayah tirinya setidaknya sekali dalam sehari. Penggunaan telepon langsung karena Darwin Marudin menurut Albert tidak tanggap dengan teknologi informasi sehingga tidak memiliki media sosial.

Sementara menurut narasumber ke dua yaitu Maria Novalia Manik meskipun ia berkomunikasi dengan ibu tirinya dalam kehidupan sehari-hari tapi hubungan Maria dengan ibu tirinya Clara Sidabutar tidak terlalu harmonis karena komunikasi antarpribadi diantara mereka diselingi pertengkaran. Menurut Maria pertengkaran tersebut biasanya terjadi karena pembagian tugas dalam membersihkan rumah. Ibu tirinya tidak bersedia membersihkan seluruh isi rumah karena ia merasa dianggap seperti seorang pembantu rumah tangga. Jadi Maria mendapatkan tugas untuk menyapu, mengepel lantai, mencuci piring dan mencuci bajunya sendiri. Menurut Maria sebenarnya tugasnya dengan ibu tirinya tidak jauh berbeda tetapi Maria merasa bahwa ia lebih sering melakukan perkerjaan rumah tangga tersebut dibandingkan dengan ibu tirinya. Hal itu Maria rasakan ketika ia sedang berada di rumah. Selain masalah pekerjaan rumah tangga maka permasalahan keuangan juga sering kali memicu pertengkaran diantara Maria dan Clara Sidabutar. Maria mengatakan bahwa ia menyampaikan kebutuhan yang ia perlukan seperti kebutuhan kuliah. Meskipun penghasilan rumah tangga yang digunakan untuk kebutuhan sehari-hari berasal dari ayah Maria namun keuangan dipegang oleh ibu tirinya.

Komunikasi antarpribadi dengan ayah tiri juga dilakukan oleh Hannas Natanael meskipun komunikasi yang terjalin antara Hannas dan ayah tirinya Herman Tanuwijaya tidak terlalu sering terjadi. Hal itu disebabkan Herman Tanuwijaya berkerja di sebuah kantin pada sebuah mall di daerah Jakarta Selatan yang dimiliki oleh ibu kandung Hannas. Meskipun demikian ketika Hannas berusaha meminta kebutuhan kuliahnya maka ayah tirinya tetap menjalankan tugas seorang ayah yaitu menafkahi anaknya meskipun Hannas bukanlah anak kandungnya. Bila uang ayahnya saat itu tidak cukup untuk membantu kebutuhan kuliah Hannas maka akan ditutupi oleh ibu kandungnya.

Hal yang sama juga dirasakan oleh narasumber keempat yaitu Haniel Natanael. Haniel mengatakan bahwa hubungan antara dirinya dengan ayah tirinya Herman Tanuwijaya dapat dikatakan cukup harmonis. Meskipun Haniel tidak pernah bertengkar dengan ayah tirinya namun ia merasa komunikasi antarpribadi yang terjadi di antara mereka kurang ideal. Sebab komunikasi antarpribadi yang mereka lakukan hanya sebagai formalitas. Topik pembicaraan mereka bukanlah topik yang sifatnya mendalam namun meluas dan umum. Biasanya pembicaraan yang terjadi hanyalah seputar pembicaraan ringan seperti Herman Tanuwijaya bertanya pada Haniel mau pergi kemana atau habis pergi dari mana. Keduanya tidak pernah terlibat pembicaraan yang mendalam seperti kesulitan Haniel di kampus atau kedekatan Haniel pada seorang perempuan. Pada saat proses wawancara Haniel juga mengatakan bahwa ayah tirinya memiliki sifat yang keras, 
tidak peduli dan egois. Meskipun begitu Haniel tetap menjalankan tugasnya sebagai anak dengan bersikap hormat kepada orang tuanya

Selain itu Komunikasi Antar Pribadi yang dilakukan oleh keempat narasumber dan salah satu orang tua tiri juga menunjukan hasil yang sesuai dengan karakteristik komunikasi antarpribadi yang diuangkapkan oleh Budyatna dan Ganiem. Keempat anak yang menjadi narasumber dan satu orang tua tiri penulis anggap memenuhi delapan ciri karakteristik komunikasi antarpribadi yaitu pertama melibatkan dua orang, adanya umpan balik atau feedback, tidak harus tatap muka,tidak harus memiliki tujuan, menghasilkan pengaruh, tidaklah harus melibatkan atau menggunakan kata-kata, dipengaruhi oleh konteks dan dipengaruhi oleh kegaduhan atau noise (Budyatna dan Ganiem, 2012: 15- 20).

\section{Simpulan}

Keempat anak dengan orang tua tirinya melakukan komunikasi antarpribadi dengan orang tua tirinya sesuai dengan karakteristik komunikasi antarpribadi. Akan tetapi dari hasil penelitian ini diketahui bahwa komunikasi antarpribadi yang terjadi antara keempat narasumber dengan orang tua tiri memiliki karakteristik yang berbeda pada setiap hubungan. Tidak semua karakteristik antarpribadi tersebut terpenuhi pada hubungan keempat narasumber dengan orang tua tiri masing-masing.

Dari penelitian ini diketahui juga bahwa anak yang mengetahui dan mengenal calon orang tua tiri sebelum menikah dengan orang tua kandung hubungannya relatif lebih baik dibandingkan anak yang tidak mengenal calon orang tua tirinya sebelum menikah. Tidak ada keterbukaan, empati, dukungan, rasa positif dan kesetaraan yang dilakukan oleh kedua belah pihak membuat komunikasi antarpribadi yang terjalin tidak berlangsung dengan harmonis

Saran penulis bagi anak dan orang tua tiri adalah hendaknya dapat saling menahan egoisme masing masing agar tidak timbul pertengkaran. Peningkatan frekuensi pertemuan antara anak dan orang tua tiri dapat dilakukan untuk menurunkan ketegangan, rasa tidak peduli dan salah paham antar satu dengan yang lain

Orang tua tiri hendaknya berusaha menjadi teman dan bukan sebaliknya ancaman bagi anak tirinya. Bagi orang tua kandung hendaknya berusaha mendekatkan orang tua tiri kepada anak agar timbul rasa nyaman dan saling menghargai sehingga terjalinnya komunikasi antarpribadi yang baik.

\section{Ucapan Terima Kasih}

Penulis mengucapkan terima kasih kepada seluruh narasumber (empat orang) yang terlah bersedia dan memberikan kerjasama selama proses penelitian ini berlangsung. 


\section{Daftar Pustaka}

Belarminus, Robertus. (Maret 24, 2015). Inikah Penyebab Konflik Anak dan Ibu Tiri?. Mei 17, 2016. Kompas Online http://megapolitan.kompas.com/read/2015/03/24/06210041/Inikah.Penyeb ab.Konflik.Anak.dan.Ibu.Tiri

Budyatna, Muhammad., \& Ganiem, Leila Mona. (2012). Teori Komunikasi Antarpribadi. Jakarta: Prenada Media Group.

Film Indonesia. (n.d.). Ratapan Anak Tiri. Mei 31, 2016. http://filmindonesia.or.id/movie/title/lf-r015-73-228039_ratapan-anaktiri\#.V0z3y 197IU

HP Records. (2015). Ratapan Anak Tiri Official Version. Mei 24, 2016. https://www.youtube.com/watch?v=Vgt8PLdzoFo

Pramesty, Gyan. (2012). Cerita Rakyat Bawang Merah Dan Bawang Putih. Mei 24, 2016. http://www.lokerseni.web.id/2012/01/cerita-rakyat-bawangmerah-dan-bawang.html 